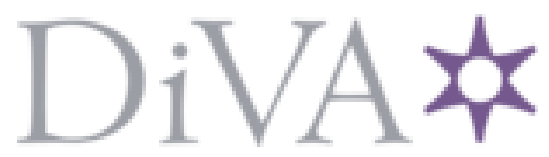

http://www.diva-portal.org

\title{
Postprint
}

This is the accepted version of a paper published in IEEE Transactions on Electron Devices. This paper has been peer-reviewed but does not include the final publisher proof-corrections or journal pagination.

Citation for the original published paper (version of record):

Malm, B., Haralson, E., Johansson, T., Östling, M. (2005)

Self-heating effects in a BiCMOS on SOI technology for RFIC applications.

IEEE Transactions on Electron Devices, 52(7): 1423-1428

http://dx.doi.org/10.1109/ted.2005.850634

Access to the published version may require subscription.

N.B. When citing this work, cite the original published paper.

Permanent link to this version:

http://urn.kb.se/resolve?urn=urn:nbn:se:kth:diva-14865 


\section{Self-Heating Effects in a BiCMOS on SOI Technology for RFIC applications}

and Mikael Östling, Fellow, IEEE.

KTH - Royal Institute of Technology, Dept. of Microelectronics and Information Technology,

P.O. Box 229, SE-164 40 Kista, Sweden, ${ }^{(*)}$ e-mail:malm@imit.kth.se

1) Infineon Technologies Sweden AB, SE-164 81 Kista, Sweden

Abstract-Self-heating in a $0.25 \mu \mathrm{m}$ BiCMOS technology with different isolation structures, including shallow and deep trenches on bulk and silicon-on-insulator (SOI) substrates is characterized experimentally. Thermal resistance values for single- and multi-finger emitter devices are extracted and compared to results obtained from 2-D fully-coupled electrothermal simulations. The difference in thermal resistance between the investigated isolation structures becomes more important for transistors with a small aspect ratio, i.e., short emitter length. The influence of thermal boundary conditions, including the substrate thermal resistance, the thermal resistance of the first metallization/via layer, and the simulation structure width is investigated. In the device with full dielectric isolation - deep polysiliconfilled trenches on an SOI substrate - accurate modelling of the heat flow in the metallization is found to be crucial. Furthermore, the simulated structure must be made wide enough to account for the large heat flow in the lateral direction.

Index Terms: Self-heating, silicon-on-insulator (SOI), thermal resistance, BiCMOS, Radio frequency integrated circuit (RFIC), electro-thermal simulation. 


\section{INTRODUCTION}

Silicon-based RFICs are suitable for a wide range of applications, ranging from low cost and low power mobile handsets to high-performance circuits in e.g. optical networking [1] and automotive collision radar [2]. The different process platforms include silicon BiCMOS, RF CMOS and SiGe HBT technology. Standard processes are enhanced with important RF components such as spiral inductors and MiM capacitors to realize RFICs [3]. Some common process concepts include the use of a thick top metal layers and high resistivity substrates to improve the Q-values of the passive components. In this context using an silicon-on insulator (SOI) substrate provides an interesting option for a dedicated RFIC process platform. In a BiCMOS platform the buried oxide will act to reduce the collector-to-substrate capacitance for the bipolar part as well as the substrate current for the CMOS devices. To achieve a full dielectric isolation of the active device area oxide or poly-silicon filled deep trenches are also used [4]. The move towards BiCMOS technology on an SOI substrate has led to many studies of self-heating effects for various isolation schemes. Some of these studies have focused on measurement-based extractions [5, 6]. Others have focused on the measurement and modelling of deep trench isolation (DTI) devices [7], SOI and bulk isolation devices [8-10], and complete dielectric device isolation structures $[11,12]$. Our work focuses on the examination of devices with three different isolation schemes from both an experimental and simulation perspective. The paper is organized in two main parts. Sections II-IV deals with the device fabrication, device results and extraction procedures for the effective thermal resistance. In section $\mathrm{V}$ finite element device simulation is used to examine the thermal properties of the different isolation structures in more detail. In particular, the influence of the buried oxide, deep trench sidewalls and the metallization on the heat propagation is studied. 


\section{DEVICE FABRICATION}

A $0.25 \mu \mathrm{m}$ BiCMOS process was used for fabricating bipolar test structures for thermal characterization. This type of BiCMOS process is typically used for radio transceivers in mobile handsets. The process includes shallow and deep trench isolation, five levels of $\mathrm{Al}$ metallization, $\mathrm{W}$ vias, low-k dielectric and typical $\mathrm{f}_{\mathrm{T}} / \mathrm{f}_{\mathrm{MAX}}$ values of $40-50 \mathrm{GHz}$.

Wafers with three different isolation techniques were fabricated for this study. The first structure featured only oxide shallow trench isolation (STI) of a depth of $0.4 \mu \mathrm{m}$. The second featured STI and polysilicon filled deep trench isolation (DTI) of a depth of $6 \mu \mathrm{m}$. Finally, the third structure featured STI + DTI on SOI substrates. This structure has a buried oxide (BOX) of $400 \mathrm{~nm}$ and a surface silicon thickness of $1.8 \mu \mathrm{m}$ (including collector epi), in which the active device is fabricated.

Processing starting materials were either $\mathrm{p}^{-}$on highly doped $\mathrm{p}^{++}$substrate for the bulk wafers, or Soitec $200 \mathrm{~mm}$ UNIBOND wafers with $200 \mathrm{~nm}$ top silicon, $400 \mathrm{~nm}$ BOX and >1000 $\Omega-\mathrm{cm}$ substrate silicon for the SOI wafers. On the SOI wafers, around $1 \mu \mathrm{m}$ silicon was epitaxially grown to obtain a thick SOI starting material with excellent top layer quality and thickness uniformity. Processing then followed the base-line process flow, including subcollector formation, collector epi deposition and STI formation. For the bulk wafers, the self-aligned shallow and deep trench isolation, as described in [13], was used. The SOI wafers also used undoped polysilicon for the trench filling, but a resist mask was used instead of the original oxide hard mask. The trench etching procedure was changed because of the buried oxide. Fig. 1 shows an SEM (scanning electron micrograph) of the completed STI + DTI structure on SOI. Processing then continued with no other differences between the bulk and SOI wafers. 


\section{DEVICE RESULTS}

The fabricated devices were characterized by both DC- as well as high-frequency S-parameter measurements up to $40 \mathrm{GHz}$. A comparison of the DC Gummel characteristics for the different isolation schemes is shown in Fig. 2. The STI + DTI wafer was taken from a previous lot while the STI and SOI wafers were processed together in the same lot. The dieto-die variation of the DC characteristics was similar on all wafers. As expected the devices with STI and STI + DTI have similar base and collector currents and identical current gain beta of $\sim 80$. However, a higher collector current and an increased current gain of 110 were observed for the devices with the full isolation on SOI. In Fig. 3. the measured SIMS profiles are shown for the SOI and bulk reference case (STI). A higher collector doping level is clearly observed for the SOI case. This difference is attributed to the presence of a buried oxide, which might affect the diffusion of the selectively implanted collector (SIC). On the other hand, the formation of the base-emitter junction is almost identical for the two cases. Therefore, we conclude that the change in effective thermal budget is small. For a baseemitter voltage $\left(\mathrm{V}_{\mathrm{BE}}\right)$ of about $0.8 \mathrm{~V}$ the base current $\left(\mathrm{I}_{\mathrm{B}}\right)$ and collector current $\left(\mathrm{I}_{\mathrm{C}}\right)$ for the SOI transistor starts to deviate significantly from the other two transistors. This sudden increase in $I_{B}$ and $I_{C}$ can be directly related to the poor thermal conductivity of the buried oxide, which will be shown by direct extraction of the effective thermal resistance $\left(\mathrm{R}_{\mathrm{TH}}\right)$ in the following section. As seen in Fig. 2, the $\mathrm{I}_{\mathrm{C}}$ has a positive temperature coefficient. For the collector bias used here, $\mathrm{V}_{\mathrm{CB}}=1.0 \mathrm{~V}$, the influence of the emitter and collector series resistances ensures a stable device operation. However, for higher collector bias thermal runaway has been observed, especially for multi-finger devices where the heat removal from the intrinsic device is less effective, corresponding to a higher $\mathrm{R}_{\mathrm{TH}}$. 


\section{SELF-HEATING CHARACTERIZATION}

To calculate $\mathrm{R}_{\mathrm{TH}}$ for each isolation structure, the extraction technique of [14] was employed. This simple and elegant technique was employed to good effect by others more recently [8]. The main part of this technique is obtaining the plot of the Early voltage $\left(\mathrm{V}_{\mathrm{A}}\right)$ as a function of $\mathrm{I}_{\mathrm{C}}$, which shows a rapid decrease in the Early voltage as the base-emitter junction is heated. The thermal resistance is calculated by using the relation:

$$
R_{T H}=\frac{Y_{22, S H}-Y_{22, n o S H}}{D_{2}\left(I_{C}{ }^{2}+Y_{22, S H} P\right)}
$$

Where $Y_{22, \text { noSH }}$ is found from $I_{C} / V_{A}$ at low $I_{C}$ and $Y_{22, S H}$ is the output conductance for high $I_{C}$, i.e. when self-heating becomes significant. In the extraction procedure the temperature coefficient of the collector current $D_{2}=\left(\partial I_{C} / \partial T\right) / I_{C}$ also needs to be acquired. Figure 4 shows the $\mathrm{V}_{\mathrm{A}}$ for several devices across the wafer for each of the three different isolation structures analyzed. The decrease in $\mathrm{V}_{\mathrm{A}}$ can be clearly seen for all three cases and is detected at low $\mathrm{I}_{\mathrm{C}}$ of between 10-100 $\mu \mathrm{A}$. Others have claimed that having high $\mathrm{V}_{\mathrm{A}}$ of $150 \mathrm{~V}$ due to the use of SiGe in the base region makes the detection of self-heating at low currents possible [8], but this result shows that the detection of self-heating can be made at low currents even for devices with $\mathrm{V}_{\mathrm{A}}$ of $10-15 \mathrm{~V}$.

The $\mathrm{R}_{\mathrm{TH}}$ for single finger devices was extracted from measured data for the three different isolation structures with a constant emitter width of $0.25 \mu \mathrm{m}$ and several different emitter lengths. Figure 5 shows a plot of $\mathrm{R}_{\mathrm{TH}}$ as a function of emitter length $\left(\mathrm{l}_{\mathrm{E}}\right)$, note that an $\mathrm{R}_{\mathrm{TH}}$ inversely proportional to $\mathrm{l}_{\mathrm{E}}$ corresponds to a straight line in a log-log plot. It is observed that the relative increase in $\mathrm{R}_{\mathrm{TH}}$, compared to the STI case, caused by the DTI and the SOI+DTI structures depends on the emitter aspect ratio, i.e., becomes more significant for 
short $\mathrm{l}_{\mathrm{E}}$-values. Comparing for example the STI and SOI devices shows an $\mathrm{R}_{\mathrm{TH}}$ ratio of 2.7 for $1_{\mathrm{E}}=7.5 \mu \mathrm{m}$ and 3.6 for $\mathrm{l}_{\mathrm{E}}=2.5 \mu \mathrm{m}$. While we do not have the case with SOI+STI, it appears that the use of DTI causes the thermal resistance to have a dependence on the emitter aspect ratio. This dependence is critical to take into consideration when determining the isolation scheme for devices. While the effect of the SOI+DTI on the thermal resistance may be acceptable for devices with a certain aspect ratio, this effect can increase quickly as the aspect ratio is reduced.

Multi-finger emitters are commonly used in RFICs transistors to match the input impedance to the system impedance of $50 \Omega$. In this study 1,2 and 4 finger transistors with a constant finger length of $10 \mu \mathrm{m}$ and pitch of $1.3 \mu \mathrm{m}$, were examined. The extracted $\mathrm{R}_{\mathrm{TH}^{-}}$ values are shown in Figure 6. Note that these points are also included in Fig. 5, which shows $\mathrm{R}_{\mathrm{TH}}$ as a function of the total emitter length. As the number of emitter fingers increases a levelling off of $\mathrm{R}_{\mathrm{TH}}$ is seen. This increase in $\mathrm{R}_{\mathrm{TH}}$ per unit length can be viewed as increased power dissipation per unit volume and hence the heat removal from the intrinsic device becomes constrained or less effective.

Figure 7 shows a plot of the cut-off frequency $\left(\mathrm{f}_{\mathrm{T}}\right)$ and the calculated increase in junction temperature $\Delta T=R_{T H} I_{C} V_{C E}$ from ambient as a function of $\mathrm{I}_{\mathrm{C}}$. It shows that under normal bias conditions even the device with only STI isolation operates at elevated junction temperatures. It also indicates that the $\mathrm{f}_{\mathrm{T}}$ is rather insensitive to junction temperature even for the case with the full SOI+DTI isolation structure. S-parameter measurements in the temperature range $27-90{ }^{\circ} \mathrm{C}$ show a peak $\mathrm{f}_{\mathrm{T}}$ variation of less than $5 \%$ with temperature for both the bulk and SOI devices.

\section{ELECTRO-THERMAL MODELING}


In order to obtain a better understanding of the self-heating in the different isolation structures and its effect on the device performance we have performed 2-D electro-thermal simulations using DESSIS-ISE [15]. The simulation structure was based on SEM cross-sections of fabricated devices and contained about 6000 - 10000 mesh points, depending on the structure width and height. The width of the simulation structure ranged from 12.5 to $75 \mu \mathrm{m}$. In particular the fully isolated structure on SOI showed significant lateral heat flow, and hence a wider structure was needed. A structure height of about $8 \mu \mathrm{m}$ was used to include the deep trenches. The electrical and the thermal simulations were performed in a fully coupled manner, using the hydrodynamic approach.

For the thermal simulations the first dielectric isolation layer and $\mathrm{W}$ vias were included, while the rest of the metallization was accounted for in a manner similar to [16] as a thermal resistances at the top of the vias. Based on the layout of the first metal layer we chose thermal resistance boundary conditions of $1.3 \times 10^{-4} \mathrm{~cm}^{2} \bullet \mathrm{K} / \mathrm{W}$ for the emitter and collector contacts. For the top oxide surface, as well as the structure sidewalls (left and right), adiabatic boundary conditions were assumed (no heat flow perpendicular to the surface). We also discuss the case where heat flow in the metallization is neglected, i.e., adiabatic conditions are assumed on top of the vias The thermal resistance $\left(\mathrm{R}_{\mathrm{TH}, \mathrm{SUB}}\right)$, representing both the bulk-Si substrate of about $700 \mu \mathrm{m}$ thickness and the wafer backside to thermo-chuck resistance, was set in the range of $100 \mathrm{~K} / \mathrm{W}$ to $1000 \mathrm{~K} / \mathrm{W}$. While the substrate thermal resistance is an important parameter for the STI case, where the dominant heat flow is directed towards the substrate, other boundary conditions should be focussed on for the DTI and SOI cases. As will be shown later, in our simulations the inclusion of the heat flow through the metallization proved to have an effect on the overall emitter-base junction temperature. Figure 8 shows the 2-D cross section of one of our simulated devices featuring both SOI and DTI. 
The same extraction technique that was used for calculating the thermal resistance in the measured devices was also employed to calculate the thermal resistance in the simulated devices. An example of part of the extraction technique is shown in Figure 9. Here we can see the impact on $\mathrm{V}_{\mathrm{A}}$ as a result of having the lattice heat flow equation turned on or off. Without self-heating there is a gradual increase in $\mathrm{V}_{\mathrm{A}}$ until the high current effects begin to occur that causes a drop in $\mathrm{V}_{\mathrm{A}}$. For the case with self-heating turned on, the effect of the increase in the base-emitter junction temperature and decrease in output resistance causes the $\mathrm{V}_{\mathrm{A}}$ to drop off in the same way as the measured devices. This graph shows that self-heating effects occurs well before the current density corresponding to peak $\mathrm{f}_{\mathrm{T}}$, i.e., before the onset of base pushout (Kirk effect).

Comparing thermal simulations in $2 \mathrm{D}$ and measured data is not always straightforward. The $2 \mathrm{D}$ simulation structure corresponds to a cut through a long emitter stripe at a position where the end effects are small, i.e., no heat flow is assumed along the length direction of the stripe. In the simulation all results are normalized to a structure depth of $1 \mu \mathrm{m}$, where depth refers to the direction along the emitter stripe, which cannot be accounted for in the 2D-simulation. Therefore, to facilitate a comparison between measurement and simulation, the measured $\mathrm{R}_{\mathrm{TH}}$-values for long stripe emitters, $(10-15 \mu \mathrm{m})$ were extrapolated (down) to a length of $1 \mu \mathrm{m}$. Table 1 summarizes the $\mathrm{R}_{\mathrm{TH}}$ results for different boundary conditions and structure widths. It is found that the thermal resistances are somewhat overestimated by the simulations. The difference in the measured and simulated values is $20-35 \%$. A comparison of $\mathrm{R}_{T H}$-values for different $\mathrm{R}_{T H, S U B}$ values, shows that a change from $100 \mathrm{~K} / \mathrm{W}$ to $1000 \mathrm{~K} / \mathrm{W}$ leads to a $10 \%$ change in the total effective $\mathrm{R}_{\mathrm{TH}}$ for the STI case. In contrast to this, the SOI structure shows no such dependence on $\mathrm{R}_{\mathrm{TH}, \mathrm{SUB}}$ since the heat flow through the BOX is very small. A comparison between 12.5 and $25 \mu \mathrm{m}$ wide simulations structures is also shown. These results indicates that a width of $12.5 \mu \mathrm{m}$ was 
slightly too small, but this effect alone cannot account for the total difference between the simulated and measured data. Furthermore, the influence of the $\mathrm{R}_{\mathrm{TH}, \mathrm{SUB}}$ value and the structure width are of comparable magnitude. Another interesting observation is that the DTI case shows the weakest width dependence, which is explained by the small heat flow through the trench sidewalls. In contrast to this more lateral heat flow (through the DTI) is occurring in the SOI device, since the BOX effectively hinders all downward heat flow to the bulk-Si substrate.

The high thermal resistance, especially for the SOI case, leads to an increased junction temperature. Figure 10 shows a plot of the lattice temperature for the three isolation structures with the vertical cut-line going through the center of the emitter at a $V_{B E}$ of $0.895 \mathrm{~V}$ and a $V_{C E}$ of $1.0 \mathrm{~V}$. The dotted section of the depth profile is the $\mathrm{W}$ via. The effect of using the SOI+DTI isolation is clearly observed with the BOX inhibiting the heat transfer towards the substrate. The effect of the metallization on the emitter-base junction temperature was also studied. Figure 11 shows the simulated cases with an adiabatic boundary condition at the via surface and with a thermal resistance boundary condition. It is very noticeable that the heat transfer through the metallization has a strong effect on the temperature distribution in the device, especially in this case with SOI+DTI isolation where the heat cannot be dissipated towards the substrate in an effective manner. This effect can be more clearly seen in the 2-D cross sections of the two cases mentioned. Figure 12 shows the 2-D cross section for the simulation with a thermal resistance boundary condition at the surface of the emitter and collector $\mathrm{W}$ via plugs. Including the vias in the simulation structure effectively changes the heat flow distribution within the isolation oxide compared to the commonly assumed case with the $\mathrm{R}_{\mathrm{TH}}$ placed at the poly-emitter surface. Compare Fig. 12 to Fig. 13 where an adiabatic boundary condition is kept at the via surfaces. Here we have much greater heating in the device region because the only place for the heat to escape is laterally through the high 
thermal resistance oxide. Also observe that due to the increase in device heating there is more heat transfer through the BOX and towards the substrate.

\section{SUMMARY}

The self-heating of a $0.25 \mu \mathrm{m}$ BiCMOS technology with different isolation structures was characterized. The three isolation structures analyzed were STI, DTI+STI, and SOI+DTI+STI. It was shown that the thermal resistance has a dependency on the emitter aspect ratio and that for smaller values the effect of the SOI+DTI becomes greater and this must be taken into consideration in device design. The use of SOI+DTI for an emitter length of $1.5 \mu \mathrm{m}$ and width of $0.25 \mu \mathrm{m}$ causes the effective thermal resistance to be 5 times as great compared to using just STI. 2-D electro-thermal simulations were performed and the thermal resistance values extracted in a similar way to the actual devices compared well. The difference is attributed to the 2-D nature of the simulations. The effect of the different isolation structures on the maximum junction temperature and thermal distribution was analyzed and it was found that the inclusion of heat removal through the dielectric isolation, vias and metallization is important, especially for the SOI+DTI+STI isolation structure. 


\section{ACKNOWLEDGEMENTS}

A. Cheshire, Applied Materials, Inc., is acknowledged for his expertise in trench etch isolation processes for SOI. This work was financially supported by VINNOVA and is part of the European Union MEDEA+ project T206 (CMOS-SOI). 


\section{REFERENCES}

[1] T. F. Meister, H. Schäfer, K. Aufinger, R. Stengl, S. Boguth, R. Schreiter, M. Rest, H. Knapp, M. Wurzer, A. Mitchell, T. Böttner, and J. Böck, "SiGe Bipolar Technology with 3.9 ps Gate Delay," Proceedings of IEEE BCTM, pp. 103 - 106, 2003.

[2] I. Gresham, A. Jenkins, R. Egri, C. Eswarappa, F. Kolak, R. Wohlert, J. Bennett, and J.-P. Lanteri, "Ultra Wideband 24 GHz Automotive Radar Front-End," IEEE MTT-S, vol. 369-372, 2003.

[3] S. van Huylenbroeck, S. Jenei, G. Carchon, A. Piontek, F. Vleugels, and S. Decoutere, “A 0.25 $\mu \mathrm{m} \mathrm{SiGe}$ BiCMOS Technology including Integrated RF Passive Components optimised for Low Power Applications," Proceedings of 33rd ESSDERC, pp. 505 - 508, 2003.

[4] K. Washio, E. Ohue, H. Shimamoto, K. Oda, R. Hayami, Y. Kiota, M. Tanabe, M. Kondo, T.

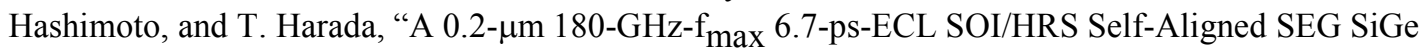
HBT/CMOS Technology for Microwave and High-Speed Digital Applications," IEDM Tech. Dig., pp. 741-744, 2000.

[5] P. R. Ganci, J.-J. J. Hajjir, C. T., P. Humphries, J. Lapham, and D. Buss, "Self-Heating in HighPerformance Bipolar Transistors on SOI Substrates," Tech. Dig. IEDM, pp. 417-420, 1992.

[6] W. D. van Noort and R. Dekker, "Thermal Resistance of (H)BTs on Bulk Si, SOI and Glass," Proc. IEEE BCTM, pp. 129-132, 2003.

[7] J.-S. Rieh, D. Greenber, B. Jagannathan, G. Freeman, and S. Subbanna, "Measurement and modeling of thermal resistance of high-speed SiGe heterojunction bipolar transistors," Proc. Topical Meeting on Silicon Monolithic Ingegrated Cicruits in RF Systems, pp. 110-113, 2001.

[8] P. Palestri, A. Pacelli, and M. Mastrapasqua, "Thermal resistance in $\mathrm{Si}_{1-\mathrm{X}} \mathrm{Ge}_{\mathrm{X}}$ HBTs on bulk-Si and SOI substrates," Proc. IEEE BCTM, pp. 98 - 101, 2001.

[9] A. Pacelli, P. Palestri, and M. Mastrapasqua, "Compact Modeling of Thermal Resistance in Bipolar Transistors on Bulk and SOI Substrates,” IEEE Trans. Electron Devices, vol. 49, pp. 1027 - 1033, 2002.

[10] M. Mastrapasqua, A. Pacelli, P. Palestri, and C. A. King, "Device simulation for advanced $\mathrm{Si}_{1-\mathrm{X}} \mathrm{Ge}_{\mathrm{X}}$ HBTs," Proc. IEEE BCTM, pp. 42 - 51, 2001.

[11] J. S. Brodsky, R. M. Fox, and D. T. Zweidinger, “A Physics-Based Dynamic Thermal Impedance Model fo Vertical Bipolar Transistors on SOI Substrates," IEEE Trans. Electron Devices, vol. 46, pp. 2333-2339, 1999.

[12] J. N. Burghartz, A. O. Cifuentes, and J. D. Warnock, "A Low-Capacitance Bipolar/BiCMOS Isolation Technology, Part II-Circuit Performance and Device Self-Heating," IEEE Trans. Electron Devices, vol. 41, pp. 1388-1395, 1994.

[13] M. Forsberg, T. Johansson, W. Liu, and M. Vellaikal, “A Shallow and Deep Trench Isolation Module for RF BiCMOS," accepted for publication in J. Electrochem. Soc.

[14] R. M. Fox and S.-G. Lee, "Scalable small-signal model for BJT self-heating," IEEE Electron Device Lett., vol. 12, pp. 649-651, 1991.

[15] I. S. E. AG, "DESSIS-ISE,", release 8.5 ed. Zurich, Switzerland, 2003.

[16] D. J. Walkey, T. J. Smy, C. Reimer, M. Schröter, H. Tran, and D. Marchesan, "Modeling Thermal Resistance in trench-isolated bipolar technologies including trench heat flow," Solid State Elec., vol. 46, pp. 7-17, 2002. 


\section{TABLE CAPTIONS}

Table 1 Extrapolated effective thermal resistance values for different boundary conditions and structure widths. 


\section{FIGURE CAPTIONS}

Fig. 1. SEM of SOI and DTI isolation scheme.

Fig. 2. Comparison of DC-gummel chararacteristics for $0.25 \times 7.5 \mu \mathrm{m}^{2}$ transistors

Fig. 3. SIMS profiles for the bulk reference device (open symbols) and the SOI device (filled symbols).

Fig. 4. Measured Early voltage as a function of collector current for $0.25 \times 7.5 \mu \mathrm{m}^{2}$ transistors with different isolation schemes.

Fig. 5. Measured thermal resistance as a function of emitter length with constant $0.25 \mu \mathrm{m}$ emitter width.

Fig. 6. Measured thermal resistance as a function of the number of emitter fingers.

Fig. 7. Cut-off frequency and junction temperature $\Delta \mathrm{T}$ as a function of $\mathrm{I}_{\mathrm{C}}$ with $\Delta \mathrm{T}=\mathrm{R}_{\mathrm{TH}} \mathrm{I}_{\mathrm{C}} \mathrm{V}_{\mathrm{CE}}$ for $0.25 \times 7.5 \mu \mathrm{m}^{2}$ transistors with different isolation schemes.

Fig. 8. 2-D cross section of device used for electro-thermal simulations.

Fig. 9. Early voltage as a function of $I_{c}$ for the simulated cases with and without self-heating.

Fig. 10. Simulated lattice temperature as a function of device depth for three different isolation structures. Cut taken through center of emitter.

Fig. 11. Simulated lattice temperature as a function of device depth for different via boundary conditions. Cut taken through center of emitter.

Fig. 12. 2-D temperature profile of SOI+DTI device with thermal resistance boundary conditions at the surface of the $\mathrm{W}$ via plugs.

Fig. 13 2-D temperature profile of SOI+DTI device with an adiabatic boundary condition at the surface of the $\mathrm{W}$ via plugs 


\begin{tabular}{|l|l|l|l|l|l|}
\hline & $\begin{array}{l}\text { Simulated } \\
(1)\end{array}$ & $\begin{array}{l}\text { Simulated } \\
(2)\end{array}$ & $\begin{array}{l}\text { Simulated } \\
(3)\end{array}$ & $\begin{array}{l}\text { Meas. } \\
\text { Extrap. } \\
1.0 \mu \mathrm{m}\end{array}$ & $\begin{array}{l}\text { Meas. } \\
2.5 \mu \mathrm{m}\end{array}$ \\
\hline $\begin{array}{l}\text { SOI+DTI } \\
{[\mathrm{K} / \mathrm{W}]}\end{array}$ & 16000 & 16000 & 14900 & 12200 & 8250 \\
\hline $\begin{array}{l}\text { DTI } \\
{[\mathrm{K} / \mathrm{W}]}\end{array}$ & 7500 & 8000 & 7850 & 7000 & 4200 \\
\hline $\begin{array}{l}\text { STI } \\
{[\mathrm{K} / \mathrm{W}]}\end{array}$ & 4500 & 4950 & 4600 & 3800 & 2250 \\
\hline
\end{tabular}

(1) $\mathrm{R}_{\mathrm{TH}, \mathrm{SUB}} 100 \mathrm{~K} / \mathrm{W}$, width $12.5 \mu \mathrm{m}$

(2) $\mathrm{R}_{\mathrm{TH}, \mathrm{SUB}} 1000 \mathrm{~K} / \mathrm{W}$, width $12.5 \mu \mathrm{m}$

(3) $\mathrm{R}_{\mathrm{TH}, \mathrm{SUB}} 1000 \mathrm{~K} / \mathrm{W}$, width $25 \mu \mathrm{m}$

Table 1 Malm et al. 


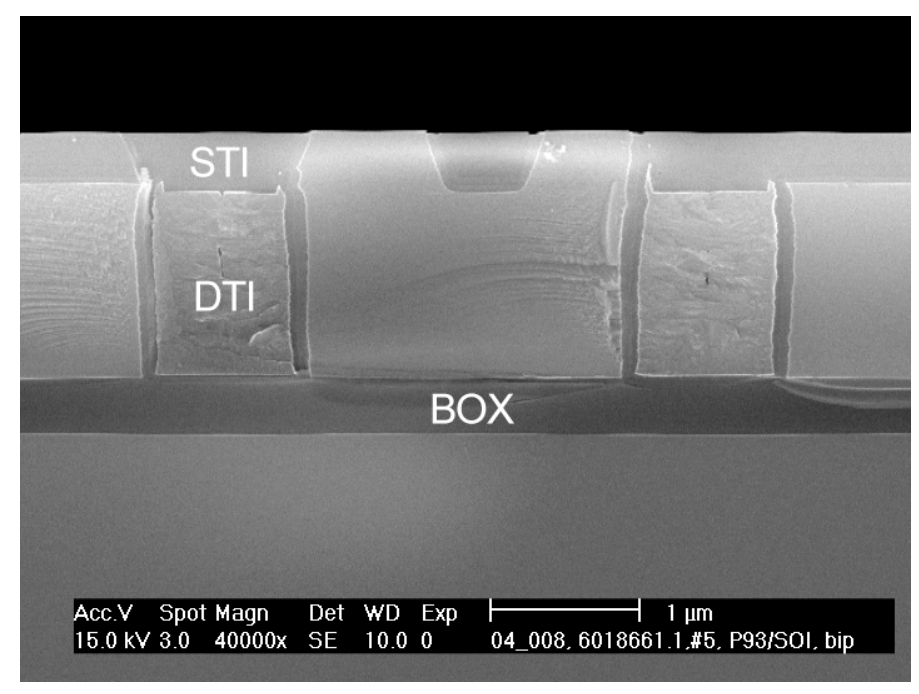

Fig. 1. Malm et al. 




Fig. 2. Malm et al. 


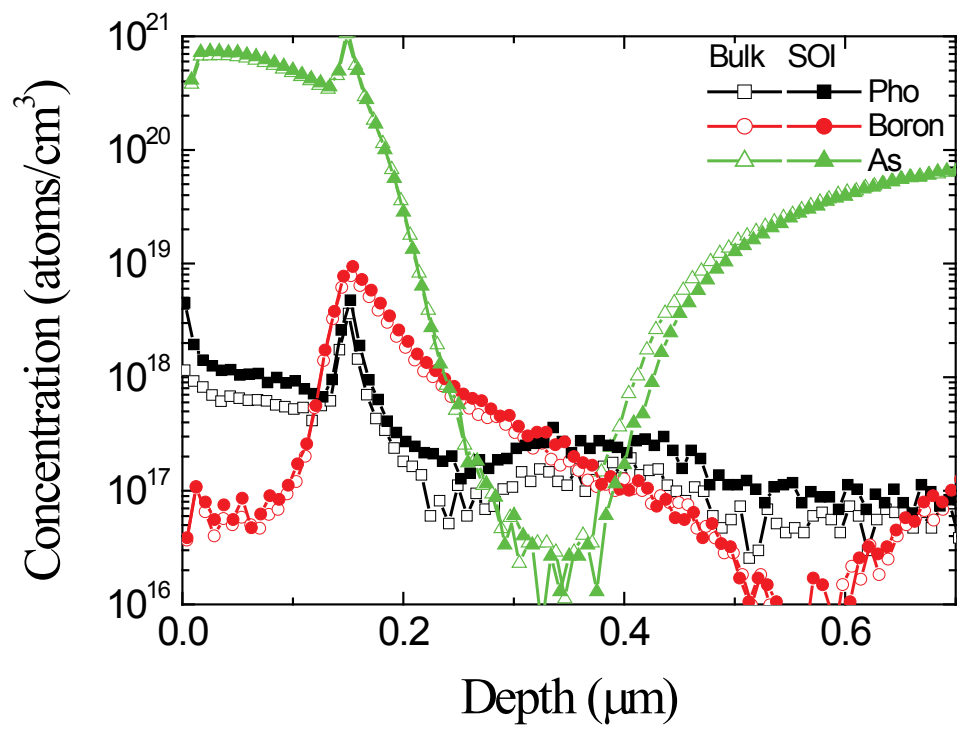

Fig. 3. Malm et al. 


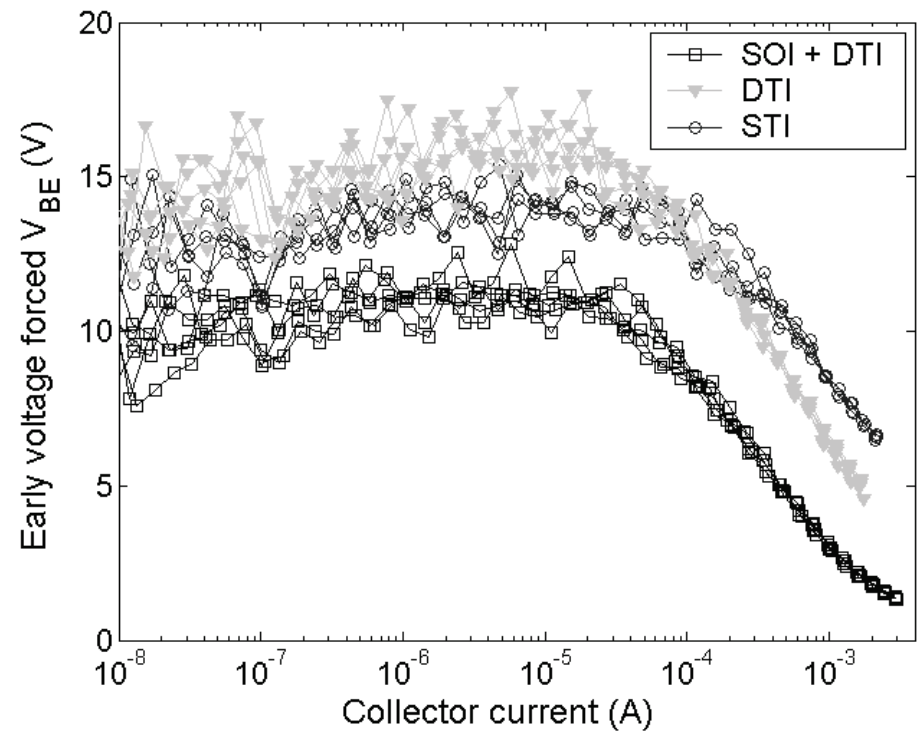

Fig. 4. Malm et al. 


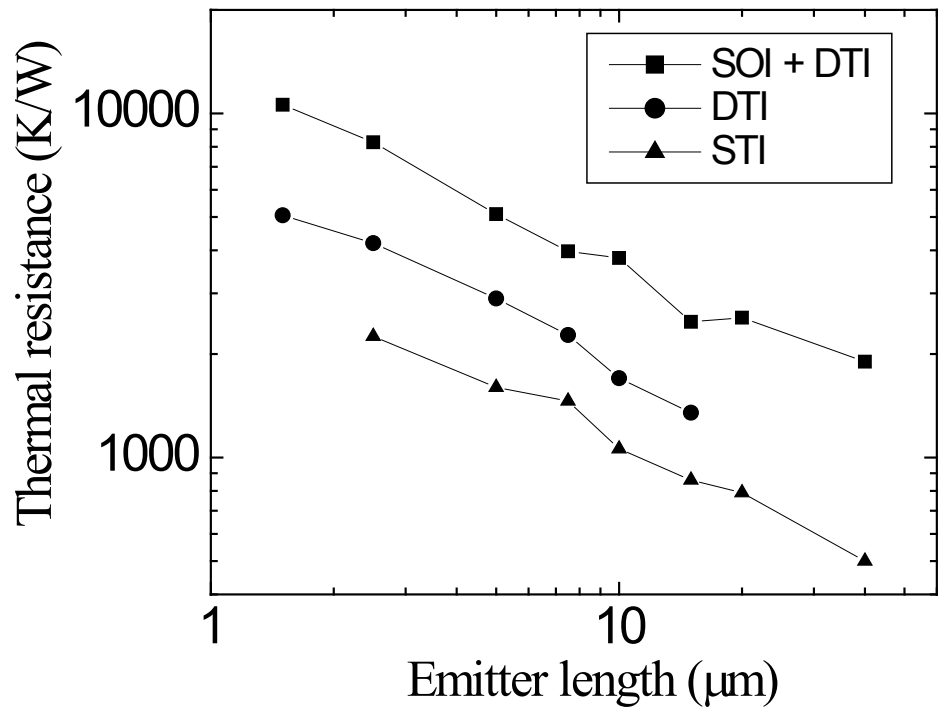

Fig. 5. Malm et al. 


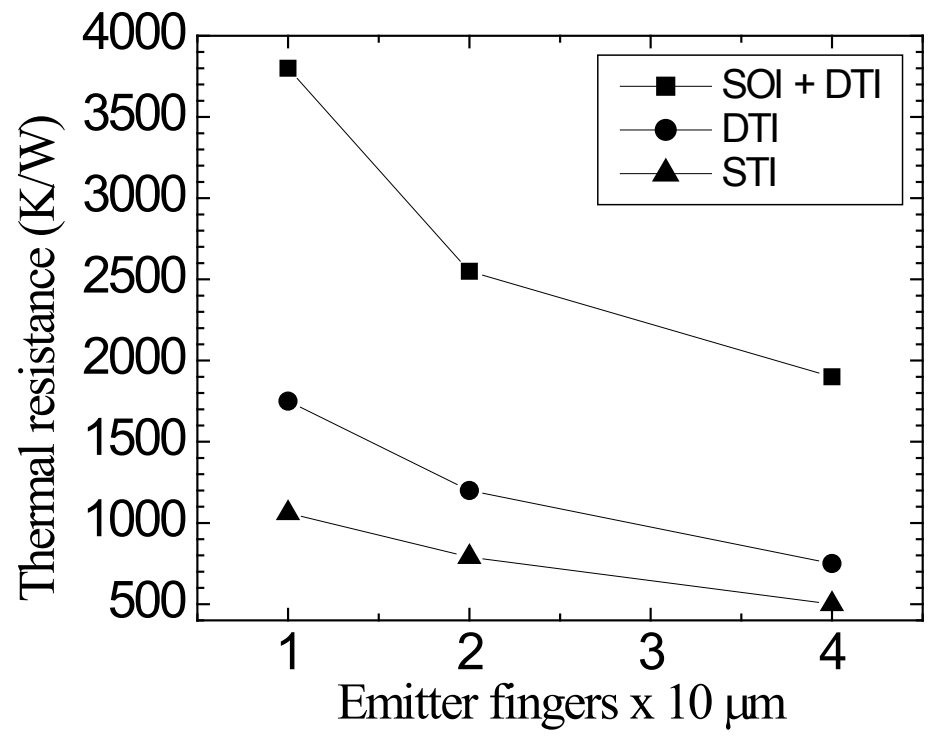

Fig. 6. Malm et al. 


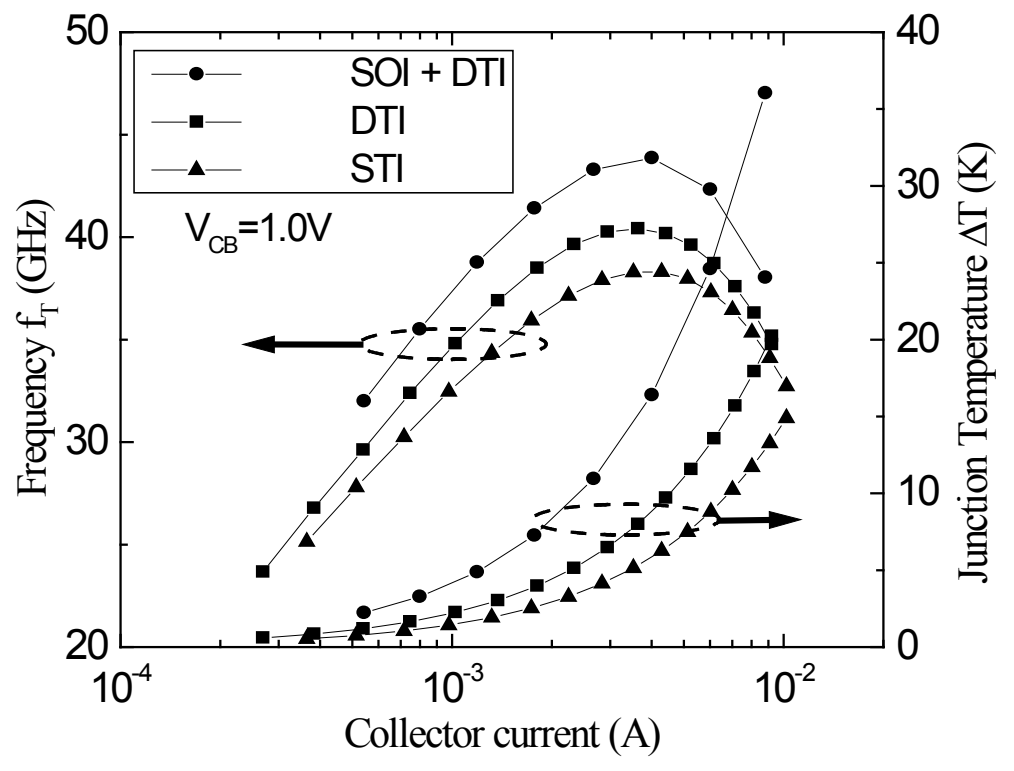

Fig. 7. Malm et al. 


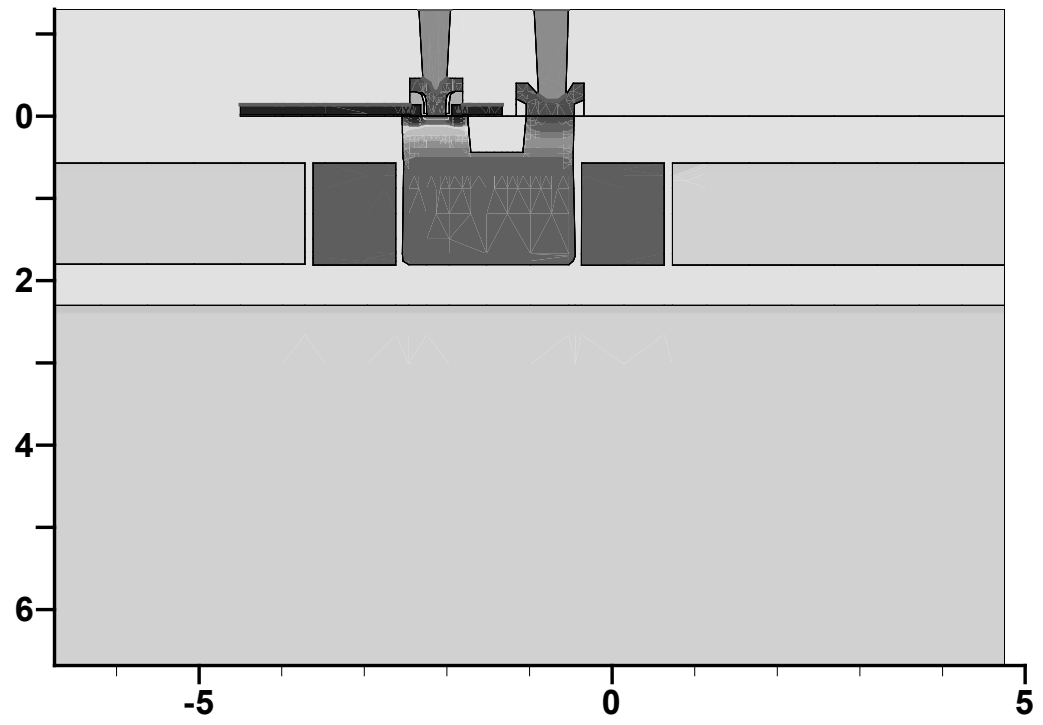

Fig.8. Malm et al. 


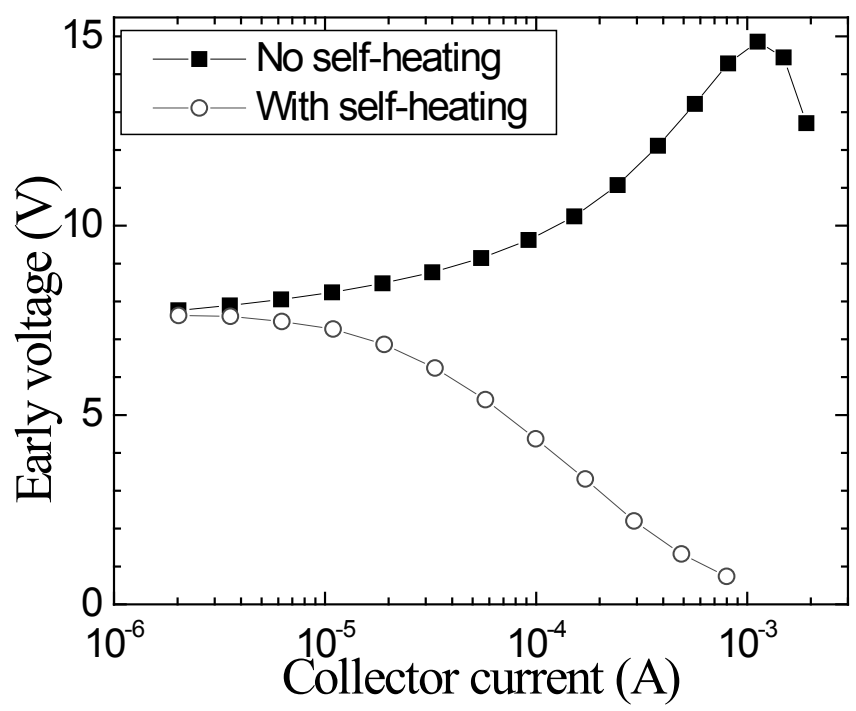

Fig.9. Malm et al. 


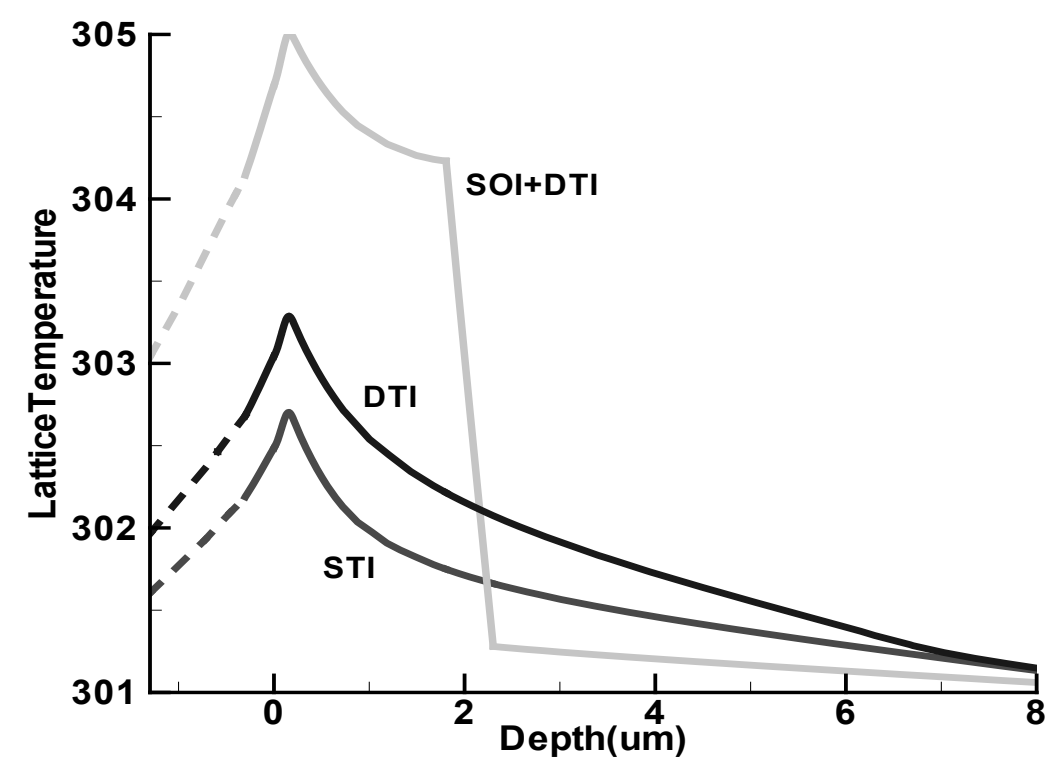

Fig. 10 . Malm et al. 




Fig. 11. Malm et al. 


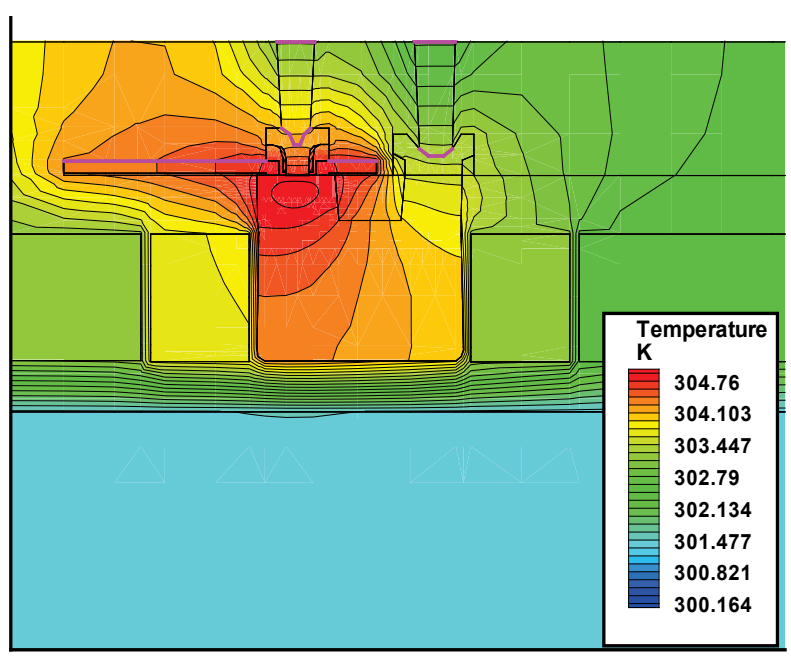

Fig 12. Malm et al. 


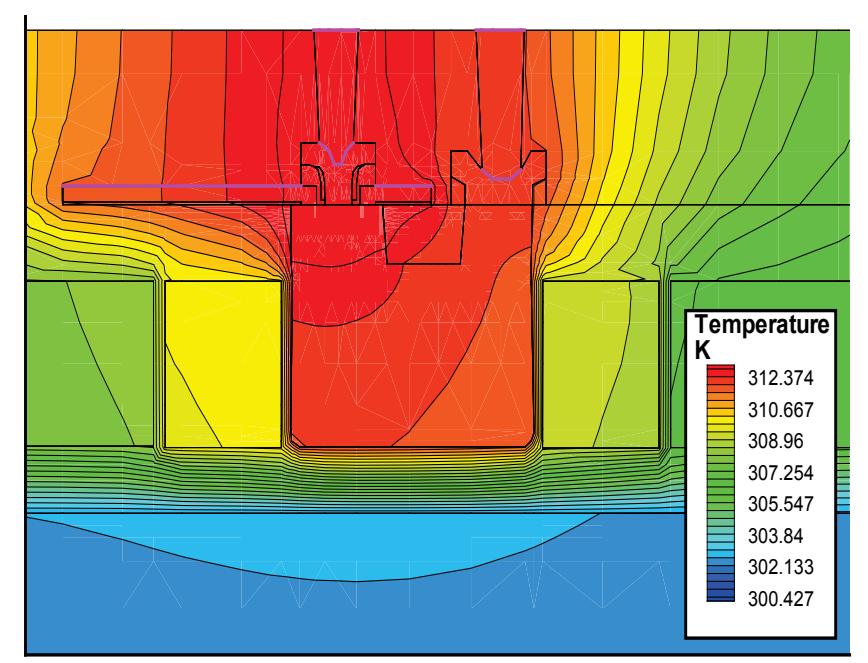

Fig. 13. Malm et al. 